\title{
Young people's experiences with clinical care and preferences for delivery of new point-of-care tests for STIs in England
}

\author{
McCulloch, $\mathrm{H}^{1}$; Pacho, $\mathrm{A}^{2}$; Geary, $\mathrm{R}^{1}$; Sadiq, $\mathrm{ST}^{2,3}$, Fuller, $\mathrm{SS}^{2^{*}}$
}

1. London School of Hygiene and Tropical Medicine; London, United Kingdom

2. St George's University of London, Applied Diagnostic Research and Evaluation Unit; London, United Kingdom

3. St George's University Hospitals NHS Foundation Trust; London, United Kingdom

* Correspondence: sfuller@sgul.ac.uk; St George's University of London, Cranmer Terrace, London SW17 ORE

Full list of author information is available at the end of the article

\begin{abstract}
Background

Young people in the UK are at high risk for sexually transmitted infections (STIs), despite STI testing being freely and confidentially available. Given multiple barriers they may face for attending sexual health clinics (SHCs), young people should be consulted regarding changes to care. Studies have shown that point-of-care tests (POCTs) for STIs, which can accurately diagnose and treat patients in one clinical visit, have potential for individual and public health benefits, yet patient opinions of changes to clinical practice associated with POCT implementation are less understood.
\end{abstract}

\section{Methods}

The Precise study explored patient experiences of UK SHC services and their opinions of POCT implementation plans; here we focus on young participants within the Precise study. Male and female attendees of three SHCs in England were purposively sampled and then invited to participate in a qualitative in-depth interview. Interviews were conducted one-on-one, in person or via telephone, were audio-recorded and transcribed. NVivo (V10) was used to organise data for our content-based analysis.

\section{Results}

Ten young people aged 17-22 years, including: three women-who-have-sex-with-men, four menwho-have-sex-with-women and three men-who-have-sex-with-men were interviewed between June 2015 and February 2016. Participants reported SHCs as the best place to receive results because treatment could be stared immediately, with advice and information available. Participants discussed the potential for POCTs to reduce anxiety currently felt waiting for laboratory results. POCTs were found broadly acceptable, and were generally regarded as an innovation to improve SHC experiences. Participants with less previous SHC experience raised concerns that implementation of POCTs could negatively affect the amount and quality of time patients spend in consultations with clinicians and that changes to pathways may cause confusion in clinic.

\section{Conclusions}

We advise POCT implementation be accompanied by SHC staff communicating changes in clinical pathways to patients, including method and timeline for receiving results. Our participants valued face-to-face counselling and advice currently experienced in SHCs; these findings emphasise that POCT implementation plans safe-guard these aspects of care. Our findings suggest that POCT implementation in SHCs has potential to improve young people's clinical experiences, which may facilitate attendance. 
Key words Point-of-care-tests, sexually transmitted infections, antimicrobial resistance, sexual health clinics, young people

\section{Background}

Young people (YP), specifically 16-24-year-olds, are one of the groups at highest risk of sexually transmitted infections (STIs) in the UK (1). In 2015, STI diagnosis rates in YP in England were twice as high in men and seven times as high in women, in comparison to 25-59-year-olds (1). STI rates remain high in YP in the UK, despite STI tests being freely and confidentially available from a multitude of sources (2). In England, YP can obtain free sexual health care and STI screening in many ways, including medical settings, such as General Practice (GP), specialist sexual health clinics (SHCs) or genitourinary medicine clinics; online, such as the National Chlamydia Screening Programme and regionally-specific services; and in some local educational environments or sports clubs (3-6). Many system-level and psycho-social barriers may prevent YP from accessing tests from any or all of these sources; long waits to be seen, judgemental staff or unfriendly clinic environments have all been shown to be deterrents (7-14). To overcome or remove such barriers, sexual health services must be accessible, non-judgmental and confidential, and deliver services for all (15). Considering this groups' disproportionate burden and distinct service needs, facilitating and improving diagnosis and treatment of STIs in YP is an essential public health measure (1).

Currently, the majority of tests for Chlamydia trachomatis (CT) and Neisseria gonorrhoeae (NG) are carried out using nucleic acid amplification tests (NAATs) performed in the laboratory, and, for NG, visual microscopy performed in specialist clinics. In 2016, the World Health Organization updated their STI treatment recommendations in response to changing antimicrobial resistance (AMR) patterns in NG, as high level resistance and decreased susceptibility to previously recommended first line treatments has been found to be widespread $(16,17)$. Although NAATs are highly sensitive to detect infections, there are no current NAATs for AMR testing in NG, and the use of these tests over microscopy detection methods has led to a reduction in antimicrobial sensitivity data collection (18). As resistance to antibiotics becomes more prevalent in certain infections, treatment options have been reduced (19). Subsequently, there are calls for health care interventions and the development of tailored treatments to reduce transmission of AMR strains to ensure that patients receive appropriate care $(20,21)$

As most NAATs for STIs are currently conducted in the laboratory, the delay between testing and receiving results can lead to onward transmission of infection (22). NAAT-based point-of-care-tests (POCTs) can deliver accurate results and allow treatment within one clinical visit (23). There is currently only one commercially-available POCT for CT and NG, which provides results in 90 minutes (24). There is mixed evidence on patient acceptability of this test in UK SHCs. In one setting, providing samples for CT/NG testing on arrival and receiving results in clinic was acceptable to $>90 \%$ patients, yet the 90 minute processing time was too long to enable testing, results delivery and treatment within one clinic visit (25). Alternately, Atkinson et al found that $<10 \%$ of patients surveyed were able to wait $>90$ minutes for results (26). To fulfil their potential, POCTs need to be acceptable to patients, especially those at higher risk of infection $(27,28)$.

The Precise study aimed to develop and evaluate POCTs for diagnosis of multiple STIS (CT, NG, Trichomonas vaginalis [TV] and Mycoplasma genitalium [MG]) and AMR detection (NG and MG). With a view to informing the potential designs and subsequent implementation of these new POCTs, the Precise study used qualitative interviews with patients to explore patients' opinions of their experiences with SHCs in the UK, and how implementation plans for POCTs might align with, and potentially affect, these patients' SHC experiences. 
This article focuses on YP within the Precise study, exploring how their patterns and views of attendance at SHCs relate to their opinions of new POCTs for STIs. 'Patterns of attendance' is a term used to describe reasons for attending, frequency of attendance or characteristics of attendees $(29,30)$. Whilst research has illuminated elements of attendance, such as reasons for attending SHCs $(2,12,14,31)$, and accompanied attendance (9), the concept of 'patterns of attendance' has not before been used as a lens through which to examine patient opinion of STI tests and testing services. Past research has focused on patient views of attending sexual health clinics, finding many negative emotions: stigma felt around clinic attendance, fear around being recognised, embarrassment at the prospect of examination and reluctance to attend due to long wait times to be seen $(11,14)$. More recently, studies have begun to ascertain the role that STI-related attitudes can have on STI screening behaviours $(32,33)$. This subset study hence addresses a gap in literature by placing young patient opinions of POCTs for STIs in the context of their experiences of SHCs and patterns of SHC attendance, with a view to providing insight for implementation of such tests and improvement of sexual health services for YP.

\section{Methods}

\section{Setting and sample}

In order to allow an iterative development of the interview topic guide (see additional file 1), the Precise study had two data collection stages. Within the first stage, 31 interviews were conducted across three NHS SHCs (in Yorkshire, Devon and London), 10 of which were with YP and form the sample for this subset analysis. YP interviews from this stage were conducted by SSF, the lead of the Precise social science study. SSF is in his early 40's, has a PhD in social science and over 15 years' experience in conducting qualitative research. Prior to the interview taking place, SSF assured all patients that any opinions, including negative opinions, of the tests or services received in the clinic(s) attended, were welcome during the interview. He presented himself to potential participants as a University researcher not affiliated with the company producing the POCT or the clinics, and explained that participants' identity would remain confidential. Participants were told that the research was being conducted so that the company producing the tests, clinicians and academics could learn patient views, and this could help promote the development and implementation of new tests that could better meet patients' needs.

The results from the main study have been reported elsewhere (34).

Participants were recruited from clinics chosen based on diversity in geographic location and model of service delivery, and a relatively high burden of infection (CT/NG), assessed in relation to PHE national averages (34). It was conceived that such variation would help determine whether differing provision or expectation of care was associated with locality and type of service.

To capture a range of experiences, patients were recruited using a purposive sampling frame based on age, gender and sexual behaviour. Participants were offered the opportunity to participate if: they were a patient at participating SHC, aged 16 - 44, willing and able to provide informed consent, could speak conversational English and had self-reported as being symptomatic for STI infection.

\section{Ethical considerations and recruitment}

The London Bridge Research Ethics Committee granted ethical approval to the project (Developing patient-centred, rapid, Point-of-Care testing including antimicrobial resistance markers for specialist sexual health services in the NHS: the Precise study social science programme project, reference 15/LO/0535) in June 2015. Favourable ethical approval for this analysis, focusing specifically on YP as a sub-group within the Precise study, was given by the London School of Hygiene and Tropical Medicine Ethics Committee on 15th May 2017, reference 13493. 
Patients were screened for eligibility by a healthcare professional. Clinic-based researchers then approached potentially eligible patients, offering the opportunity to participate in an interview. Those interested in participating provided their first name, ethnicity, contact details, and their preference for time of contact from the research team. These patients received a patient information sheet and were given at least 24 hours to consider taking part in the study before contact was made by the research team to arrange an interview. Interviews were carried out one-toone, either face-to-face or via telephone, depending on participant's preference. Out of regular working hours and weekends appointment slots were offered. Prior to the interview, patients provided full informed consent to participate in the study. Participation was voluntary, and participants were able to withdraw from the study without affecting their medical care. Participants were assured of confidentiality and anonymity.

All participants were given identifiers that were used throughout the research process to pseudoanonymise participation. During analysis and write of up of this manuscript, the $10 \mathrm{YP}$ in this sample were given randomly assigned letters, and will be referred to as respondents A-J.

\section{POCT configuration, interview topic guide preparation and hypothetical changes to clinical pathway}

The POCTs in development (binx health) within the Precise study have potential to be implemented in various ways. At the start of the study the design for the POCT cartridges was not yet known. Several cartridge designs for diagnosis and AMR detection were explored, to better understand the acceptability of performing one or several tests in succession. For example, one cartridge could include CT/NG plus NG AMR detection, with TV/MG plus MG AMR detection on a separate cartridge. This design could mean that patients would wait for the results of their CT/NG plus NG AMR cartridge results, and if no infection was detected would then be offered the TV/MG cartridge as a secondary, or reflex, test. Similarly, we explored the possibility of a multiplex infection diagnosis cartridge (e.g. CT/NG/MG/TV), with those with positive infection detection for NG or MG receiving a reflex test for AMR strains before receiving treatment. Each of the cartridges produced would have potential to provide results in approximately 30 minutes; how the cartridges were designed, and how many needed to be used per patient, has potential to impact the overall time for patient diagnosis and treatment.

Informal interviews with clinicians at participating clinics informed development of the patient interview topic guide, exploring the various cartridge configurations and translating them into potential clinical pathways and tangible scenarios upon which participants could comment. Discussions with clinicians explored views of the need for STI and AMR detection NAAT-POCTs for specific patient populations, as well as preferable cartridge design(s) and potential implementation pathways.

Some hypothetical new clinical pathways began with self-sampling upon triage - an aspect of the POCT that is already in place in some SHCs in the UK (35). Self-sampling upon triage is a clinical pathway that would include: on arrival at the SHC, patients would be asked to fill in a triage form; if their triage forms indicated they would be eligible for testing using the POCTs they would be asked to take their own swabs (vaginal, anal and or pharyngeal, as appropriate) and/or provide a urine sample before seeing a clinician. Other questions in the topic guide explored scenarios that came from the various cartridge configurations, a second (or reflex) test for additional infections upon negative results for infections tested by the first cartridge, or for AMR detection upon positive infection results from an initial cartridge. Participants were also presented with the situation where they would receive results for some infections during the clinical visit, that same day, and receive 
other results via text within 5-10 working days. For example, receiving CT results in clinic, but then waiting for HIV results at home. To facilitate conversation and encourage participants to develop their responses to questions asked by the interviewer, the topic guide included prompts.

The topic guide was piloted in the first few respondents; after preliminary analysis it was seen that the guide elicited robust and relevant responses and it was decided that no changes were necessary and the initial respondents were included in the main analysis.

\section{Data analysis}

Formal data analysis occurred after completion of data collection. Interviews were audio recorded using a digital device and transcribed verbatim. Two members of the study team (SSF and AP) then checked the transcripts, assessing their accuracy against the audio recordings. Transcripts were not returned to participants for comment.

We used a content-based analysis approach commonly used in applied qualitative health research. SSF, AP and HM first familiarised themselves with the data by reading paper copies of the transcripts; SSF and AP read transcripts for all participants involved in the Precise study, whilst HM only read transcripts for the 10 YP in this subset analysis. NVivo (V10) was used to organise data and develop coding. HM coded the data. Codes were constructed from inductive and deductive themes arising from reoccurring themes across the interviews and from a priori topics relating to the interview topic guide. Theme development was discussed amongst the study team at several stages as coding was taking place. The coding tree can be found in additional file 2 .

Once coding was complete, four interviews were chosen to create in-depth participant profiles on paper charts. These specific interviews were selected as they covered a range of attendance patterns and sexual behaviours; two men-who-have-sex-with-women (MSW), one woman-who-hassex-with-men (WSM) and one MSM; one first-time attender, two participants who had attended a clinic on multiple occasions, and one participant who reported habitual attendance. The creation of these profile charts aided the visualisation of themes across participant's patterns of attendance (reasons for attending, frequency of attendance and attending with friends), views of attendance and opinions of new POCTs. Comparison across these charts allowed us to explore patterns of association, defined as "connections between two or more phenomena" (36), in this case, the relationship between participants' patterns of attendance and their views of tests. One pattern of association was taken forward, as this pattern was also found within the remaining six participant interviews (36). To ensure reliability, codes and patterns of association were checked and confirmed by the study team at various stages during analysis.

\section{Results}

\section{Participants: characteristics and patterns of attendance}

A total of ten interviews with YP took place in the first stage of data collection within the Precise study June 2015 - February 2016. Young participants were: 5 individuals from London, 3 individuals from Yorkshire and 2 individuals from Devon. Interviews lasted between 31 and 75 minutes.

Each clinic had different approaches for identifying potential participants and hence data cannot be given on those patients who declined to supply contact details to recruiters. However, levels of attrition between agreement to provide contact details to the study team and completion of an interview are available. Failure to respond to three contact attempts to schedule an interview or failure to attend an organised interview were taken as passive refusals. Attrition varied greatly across clinics. Among young participants: $62.5 \%$ (5/8) of London-based patients, 50\% (3/6) of Yorkshire-based patients, and $12.5 \%$ (2/16) of Devon-based patients who supplied contact details completed an interview. 
Participants were aged 17-22 years (mean age: 20 years), reported to being either White (British or other) or Asian British. Full demographic details of participants are provided in table 1, in addition to details of individual patterns of attendance including reasons and frequency of attendance, and whether participants attend with friends.

Table 1 Participants' characteristics and patterns of attendance

\begin{tabular}{|c|c|c|}
\hline Characteristic or pattern of attendance & & Total \\
\hline \multirow[t]{2}{*}{ Gender $^{*}$} & Female & 3 \\
\hline & Male & 7 \\
\hline Age (years) ${ }^{\star a}$ & $\begin{array}{l}17-19 \\
20-22\end{array}$ & $\begin{array}{l}3 \\
7\end{array}$ \\
\hline Ethnicity $^{*}$ & $\begin{array}{l}\text { White: British \& other } \\
\text { Asian British }\end{array}$ & $\begin{array}{l}9 \\
1\end{array}$ \\
\hline Sexual behaviour* & $\begin{array}{l}\text { MSM } \\
\text { MSW } \\
\text { WSM }\end{array}$ & $\begin{array}{l}3 \\
4 \\
3\end{array}$ \\
\hline Education** & $\begin{array}{l}\text { University } \\
\text { College } \\
\text { College/Apprenticeship }\end{array}$ & $\begin{array}{l}7 \\
1 \\
2\end{array}$ \\
\hline Children** & $\begin{array}{l}\text { Yes } \\
\text { Not discussed }\end{array}$ & $\begin{array}{l}1 \\
9\end{array}$ \\
\hline Living situation** & $\begin{array}{l}\text { Shared housing } \\
\text { With parents } \\
\text { Varies depending on term time } \\
\text { Alone (with son) } \\
\text { Not discussed }\end{array}$ & $\begin{array}{l}3 \\
2 \\
3 \\
1 \\
1\end{array}$ \\
\hline Reasons for attending **b & $\begin{array}{l}\text { Symptoms } \\
\text { Health scare } \\
\text { Appropriate time to get checked }\end{array}$ & $\begin{array}{l}8 \\
1 \\
1 \\
\end{array}$ \\
\hline Frequency of attendance ${ }^{\star \star c}$ & $\begin{array}{l}\text { First time }{ }^{d} \\
\text { Multiple visits }^{e} \\
\text { Regular attender }\end{array}$ & $\begin{array}{l}2 \\
5 \\
3\end{array}$ \\
\hline Attends with friends ${ }^{\star *}$ & $\begin{array}{l}\text { Yes } \\
\text { No }\end{array}$ & $\begin{array}{l}4 \\
6 \\
\end{array}$ \\
\hline \multicolumn{3}{|c|}{$\begin{array}{l}{ }^{*} \text { Self-reported during study recruitment } \\
{ }^{*} \text { Self-reported during interview } \\
\text { a Although the sampling frame included YP aged 16-24 years, no participants were aged 16, } 23 \text { or } 24 . \\
{ }^{b} \text { Some participants mentioned primary and secondary reasons for attending. Listed is the primary driver } \\
\text { of attendance. } \\
\text { " Frequency of attendance here is divided into three categories: } \\
{ }^{d} \text { First time attenders have only attended a SHC once, but may have been tested in non-medical } \\
\text { community settings, (e.g. a youth centre). } \\
\text { e Those who have visited multiple times described at least two different clinic experiences, but not talk } \\
\text { about attending regularly. } \\
\text { fRegular attenders will refer to when they "usually" use Sexual health services, when they attend for } \\
\text { normal or general check-ups at periodic intervals. }\end{array}$} \\
\hline
\end{tabular}

Findings will be presented under two headings: positive opinions of POCTs as an innovation that could improve SHC, and concerns about POCTs.

\section{POCTs and their ability to improve the sexual health clinic experience Reducing time in clinic, reducing wait times, reducing anxiety}

It was very common for participants to report negative feelings towards aspects of their SHC experience; more than half of YP mentioned feelings of anxiety, apprehension, discomfort or embarrassment due to SHC attendance. Participants with varying levels of SHC experience described attendance as an unpleasant ordeal, when recounting first-time, recent or habitual experiences. This individual described feelings of embarrassment at unexpected events on his first SHC visit. 
"I was like uncomfortable, because there was a female doctor in here as well, and there was two doctors and I've never been to clinics before in my life...And they made me get on the table, and that was quite uncomfortable...

Respondent D, 18-year-old MSW, London

Referring to how he usually feels waiting at SHCs, one individual outlined his thought processes whilst waiting to see a clinician, reflecting on what brought him to clinic.

"I mean, anxious... because most of the time if I've gone to the clinic it's because I've had, like, sexual contacts, usually unprotected contacts, that's spurred me to go to the clinic, so, like, embarrassed by myself, pretty disgusted in myself, really anxious...and then you're just waiting. .... So, yes, it's not a nice experience"

Respondent J, 21-year-old MSM, Devon

Several attendees outlined strategies they had used to make the experience less unpleasant, for example going with friends.

"At least if you go together ... it's a bit less intimidating...I guess we decided to make ... the best out of a situation that's not really normally that pleasant to do"

Respondent F, 22- year-old WSM, London

Almost half of this group of YP described POCTs as a welcome way to alleviate anxiety felt when waiting for test results. This patient outlined how the test may reduce the distress felt in the interim period between current testing and diagnosis.

"It [receiving results in the same visit] would be a lot better than waiting that week in the, that sort of, like, build-up, that apprehension... it [the POCT] speeds everything up, people won't be waiting as long."

Respondent H, 19-year-old MSM, London

Many participants were enthusiastic at the potential they saw for POCTs to reduce the time they currently spend waiting in clinic. However, implementation of POCTs may not lead to reduced time spent in clinic, as many current clinical pathways, dependent only on patient sample provision being sent to the laboratory for testing, take less time than the expected 30-minute turnaround time for the new POCTs. This point was always clarified by the interviewer. However, for two young MSW, it was the prospect of a shortened visit to a SHC that was the most positive aspect of POCTs.

"Everyone wants to like spend as less time as they possible can...No one really wants to be here. They just want to get in and out, and if it's quicker it's better obviously"

Respondent D, 18-year-old MSW, London

\section{Being in the best place to receive results}

A large proportion of those interviewed were excited for the POCT to provide patients with their results in clinic; they described SHCs as the best place to receive a diagnosis, since treatment can begin sooner:

"It is much better to get the information whilst you're there [in clinic] so you can start the process of fixing whatever is wrong with you" 
The clinic was not only the best place to receive results since it allowed for immediate start of treatment, but also because of several assumptions about what clinic attendance meant. For one participant, it was not just the idea of receiving results that same day but also receiving results in a setting where he imagined that he would be provided with information, guidance and care. Rather than a brief text message with a diagnosis that might appear at any time, this participant's expectation of receiving results in clinic was to leave more informed, with a plan of action for treatment.

"It would be a great comfort to me if I was told, right, I've got Chlamydia, and I don't know what the next step is... but I'm at the clinic so I can ask. Like they're saying to me, look you've got Chlamydia but this is what we're going to do, and this is how long it'll take to get the medicine... you know all those things. ... to know that straight away is much better than... me thinking that you know, it's a Wednesday, I'm sat at the university, I just look at my phone and I've got a text saying, look you've got Chlamydia"

\section{Concerns about POCTs}

Respondent A, 22-year-old MSW, Yorkshire

Whilst participants with varying levels of experience of SHCs described POCTs as an improvement, some specific concerns, specifically regarding the process of testing and receiving results, privacy, patient-centred care and information regarding the new pathway and wait times, were raised by those who were infrequent SHC attenders (e.g. described never having been to a SHC prior to the appointment where they were invited to interview, or described $\geq 2 \mathrm{SHC}$ experiences but did not describe themselves as 'regularly attending' SHCs).

\section{POCT guidance and confusion in clinics}

Several participants, who were infrequent SHC attenders, emphasised a need for information to accompany the new POCTs. Concerns were specifically raised around knowledge of the new pathways, being made aware of how long they would be waiting or being instructed on selfsampling. Knowledge of the new POCT pathways and their duration was also discussed by this young person, who, when discussing the possibility of reflex testing for AMR upon a positive gonorrhoea diagnosis, stated:

"These... incremental times that you've been giving me so far... 30 minutes for the Chlamydia test, 30 minutes to wait for the resistance test, that's fine, having that information is the most important thing... knowing when these tests will be ready, and knowing when you're ready to take them, and how long it will take, is a big part of it."

Respondent A, 22-year-old MSW, Yorkshire

When discussing that a patient may end up spending more time in clinic waiting for POCT results than they currently spend in clinic, this participant highlighted the importance of knowing roughly how long it would take and being told about waiting times in advance.

"Somebody who thinks they're going to be there for one 30 minute test and is then told, ... you might need another 30 minute test, for them [it] might be kind of pushing it a bit if they're not told in advance that they might need a second test."

Respondent G, 21-year-old MSW, London

A need for communication from SHC staff about new POCT pathways was also raised by several participants who highlighted a lack of clarity in general at SHCs. Two participants described confusion about what you should do and where you should be at the SHC. This first-time attender described such feelings in an unfamiliar environment. 
"I wasn't quite sure how to go about it, usually when I go to a GP it's a case of go to reception, wait, get called, but they had, like, three different waiting rooms which kind of confused me... it's all a new experience for me"

\section{POCTs and privacy}

Respondent G, 21-year-old MSW, London

Some participants, also infrequent SHC attenders, raised concerns about providing self-samples at reception, highlighting their concerns about how to self-complete sampling kits, feelings of embarrassment, and wishes for more privacy in SHCs. When discussing self-sampling, one individual expressed a desire to maintain anonymity and secrecy during his visit, not wanting others to know what tests he might need.

"You'd be quite shocked if ... at the reception suddenly you got a pot and swabs ... you don't want people to see what tests you're doing, you don't want people to see forms... you want it all to be you know as segregated as possible."

Respondent A, 22-year-old young MSW, Yorkshire

Privacy was also on the minds of other participants, when discussing methods of receiving results. One participant, when asked if there were any situations when he would not wish to receive results in the same clinical visit as testing, responded as such:

"Unless I was with someone...And I wanted to keep it personal to me. See if someone came with me, and they told me there and then, I wouldn't want the other person to know"

Respondent $D$, 18-year-old young MSW, London

\section{POCTs and preferences for sexual healthcare}

Some participants voiced concerns about the potential effects POCTs may have on patient care and interactions with staff, something valued by many participants. One participant expressed a wish that clinicians continue to take their full sexual history, even if they are aware of their diagnoses following a POCT. This participant emphasised the need for holistic care, which should not be compromised by the potential for reduced time spent with clinicians that POCTs may provide.

"Even if it does mean quicker results and quicker this and quicker that, if it makes the person feel... uneasy or a bit, you know, I still think that... the patients should be treated... as a whole rather than ... here's your result, okay, here's your treatment, get out..."

Respondent F, 22- year-old WSM, London

The theme of patient-centred care was returned to many times by this young woman, highlighting its importance in her SHC experience and expectations. Reflecting on her first time attending a SHC, she recollected how one nurse had been particularly supportive.

"She just sat there and she just talked to me, not only about why I was here... how I was feeling about all the situation and so it was more like... counselling than it was just to go get checked out..."

Respondent F, 22-year-old WSM, London

Reflecting on a relationship established with a particular member of staff at a sexual health clinic she attends, another female participant showed her appreciation of the support and guidance provided by clinicians, alongside clinical care and treatment. 
"I feel more comfortable with her [one particular doctor]... Than I do with anybody else because I feel like, even though I don't know her, but I feel like I know her here ... it's like she goes at me like my mum... You know, we've had this talk, you know, how many times? And I'm, like, I know, this is going to be t'last time you see me, I promise."

Respondent C, 21-year-old heterosexual woman, Yorkshire

Referring more explicitly to the informational support provided by clinic staff, one participant mentioned, whilst discussing his experiences within two different SHCs, how SHCs can facilitate sex education by providing more comprehensive and relevant information about sexual health than sex education available in school.

"Um, what do you need the most? ... help you know, privacy and just information, because that's all I'm coming here for, I think. Um, so sex education in schools is, at least in my experience, wasn't great.... So coming to places like this is in a private setting where you can get honest information, and just, you know, that sort of reassurance that you're okay, just like [what you want from] a doctors' appointment, a GPs appointment; you want information about what might be wrong with you, you want to make sure that you're okay. So I think it I just [want] that sort of private consultation for comfort I guess, comfort and information."

Respondent A, 22-year old MSW, Yorkshire

\section{Discussion}

This study provides new insight into YP's opinions of new POCTs and potential implementation in a UK setting. Clinicians' opinions regarding POCT configuration have been studied previously $(23,34)$, Prior to POCT implementation across SHCs, patients, especially groups at high risk for STIs, should be consulted on POCT acceptability $(25,26)$. Our findings are in line with findings from previous research that has explored YP's attitudes and experiences towards SHCs and STI screening more generally, as well as barriers to clinic attendance.

YP in our study saw POCTs as an innovation that would reduce waiting times and anxiety felt around testing and clinic attendance. Such findings echo Normansell's research into young women's attitudes and access to SHCs, which identified long wait times as a barrier to regular screening attendance at SHCs (14). Anxiety around testing and receiving results is a common theme in research around YP's experiences of SHCs (7-11). In addition to psycho-social factors such as stigma, embarrassment and fear of judgement, anxiety has been found to be a barrier to clinic attendance (8-13). Several studies have explored the association between attitudes towards SHC attendance and screening behaviour in young people; a study involving young people from the UK, the United States and Canada found that having a negative attitude towards visiting a clinic was negatively associated with screening, whilst a study of Dutch young people found that attitudes toward attending SHCs to be biggest predictor for attendance. $(32,33)$. Hence, improving YP's experiences at sexual health clinics may encourage attendance.

Participants discussed how POCTs would allow treatment to commence immediately, a finding mirrored in Rompalo et al's (37) research into users' POCT preferences. Whilst our findings agree with Rompalo's, the two studies vary in focus, setting and time period. Through focus groups carried out in the United States between 2008-2009, Rompalo's study explored the advantages and disadvantages of rapid tests in clinics, as well as perceived barriers to use of POCTs in both clinic and home settings. In Rompalo et al's study, participants discussed characteristics of an ideal homebased rapid diagnostic, imagining an over-the-counter POCT, somewhat like a pregnancy test. Unlike Rompalo's study, our study did not explore envisioned characteristics of an ideal POCT, but, in 
order to inform design, development and delivery of new rapid diagnostics, presented participants from various UK clinics with hypothetical yet realistic changes to current clinical pathways.

Participants in our study described how POCTs would enable receipt of results in their ideal setting, which participants described as SHCs because medical advice and counselling would be available alongside treatment. This finding is particularly important to consider in the context of a recent move from face-to-face consultations to online services, which will enable people to order at-home testing kits and receive results via text message. As part of a new collaborative commissioning model for sexual health services in London (London Sexual Health Services Transformation Programme), since January 2018, asymptomatic patients have been directed away from SHCs and encouraged to use these new online services $(38,39)$. Research has shown online services to be an effective measure to increase uptake of STI testing, but also recommends that they be considered as a complement to existing services (40). At an early stage of service provision, a study comparing characteristics of clinic and online users in Lambeth and Southwark, found that online users had significant demographic differences compared to clinic patients and were less likely to be diagnosed with chlamydia or gonorrhoea (41). Although providing an important resource for some patients to receive sexual health infection screening without attending clinic, remote testing and treatment may miss an important aspect of YP's sexual healthcare needs. Our study indicates that YP highly value face-to-face medical advice and counselling currently received in SHCs. When discussing POCT implementation, some participants raised concerns about how POCTs would affect the level of patient-care, such as results being given in a hasty manner before participants had the opportunity to discuss their reasons for attending.

The YP in this study also emphasised the importance of information and guidance around testing pathways and self-sampling processes. In line with findings in other research with YP $(9,10,42,43)$, emotional and informational support from staff was seen as an essential aspect of sexual health services for our participants. This also reflects recent research into YP's attitudes towards innovation in sexual health care; a study exploring YP's perceptions of smart-phone enabled self-testing pathways found that patients were excited by the prospect of a technology that would remove the need to face embarrassing and uncomfortable clinic visits, however this was somewhat mitigated by concern about receiving diagnosis and treatment without contact with a healthcare professional (44). Both in Aicken et al's study and this study, YP were excited about the prospect of a change that might improve their sexual health care seeking experience, but reiterated the importance of the role of the health care professional in YP's experiences at clinic. Thus, we suggest that implementation of POCTs into clinical pathways not replace or reduce the face-to-face contact with sexual healthcare professionals that YP value in their care experiences.

\section{Strengths and limitations}

It should be acknowledged that this study sample is not particularly ethnically diverse, with nine white and one Asian British participant. Whilst this does broadly reflect national ethnic distribution (45), as this project's findings relate to barriers for SHC attendance and fears around stigma and privacy, it should be recognised that some ethnic minorities have been found to be more concerned about these issues than white attendees $(13,46,47)$. In a study comparing SHC experience between ethnic minority and white British MSM, men from an Indian, Pakistani or Bangladeshi (IPB) background were more likely to be anxious or uncomfortable at the prospect of attending a SHC, and more concerned about being overheard or seen in the waiting area (13). In the same study, IPB men also feared others from their community finding out they have sex with men, as did black Caribbean and black African respondents, while very few white MSM reported these concerns (13). In the UK, individuals who identify as ethnically black experience a disproportionate burden of HIV and STI (48). Compared to white ethnic groups, rates of gonorrhoea are 8-12 times higher among people of black Caribbean ethnicity $(49,50)$. Nationally representative studies have reported that a 
higher proportion of individuals identifying as black Caribbean attend SHCs than white/white British individuals $(51,52)$. Whilst there were three participants of 30 , who identified as black or black British within the main Precise study, there were none in the YP sample.

Apart from ethnicity, this sample reflects a range of YP with different backgrounds and behaviours and diverse characteristics and patterns of attendance. Our participants from three different locations across England included YP living at home and independently, with different educational statuses and one young mother; our sample speaks to the fact that YP are not a homogenous entity. In addition, variation within participating clinics' care pathways, and patients' past attendances at different SHCs across the country, gave us the opportunity to explore a broad range of SHC experiences. Such diversity speaks to the current context of sexual healthcare in the UK, which has been criticised as "complex and fragmented" since organisational changes were made in 2012 (53). Although the POCTs in development have yet to be implemented into care, we believe the diversity of SHC settings, pathways and experiences YP describe in our study are likely to be reflective of actual implementation of POCTs and their consequences for young patients in England.

\section{Conclusions}

Our findings are a timely and important exploration of YP's opinions of new POCTs for STIs. They give insight into inter-related STI treatment preferences and sexual healthcare-seeking experiences, in a group who bear an increased burden and risk for STIs. Placing young patient opinions of POCTs for STIs in the context of their views and experiences of SHC attendance, has not only borne recommendations for implementation which are grounded in patient experience, but also acknowledged and explored the diversity of experience of this particular group recruited from SHCs across the UK. Such variation in SHC experiences and expectations have highlighted that specific SHCs' organisational structures, pathways and processes should be considered when implementing POCTs.

Bearing much of the burden of infections such as CT and NG, YP are a group at risk for STIs (1). Despite the broad array of free and confidential testing settings in the UK, STI rates remain high (2). Research has shown that YP experience many barriers to accessing sexual health services $(2,8-14)$. To overcome such obstacles and effectively meet this group's sexual health needs, services must adopt youth-friendly processes (15). This commitment should not only extend to current service provision, but also to future developments (28). POCTs have the potential to not only combat AMR in STIs and reduce spread and burden of infection, but also improve YP's SHC experiences. Such tests are becoming commercially available and may soon be implemented into healthcare services. Hence, under 25s should be consulted on potential changes to care-pathways in SHCs brought about by these rapid diagnostics, and their views incorporated into recommendations for POCT implementation at SHCs (see table 2).

We recommend that POCT implementation be accompanied by effective communication from staff regarding the clinical pathway and method and timeline for receiving results. YP value the quality of SH care, face-to-face interactions, counselling and advice from clinicians; we strongly recommend that implementation of POCTs into clinical pathways include safe-guarding these aspects of care. Changes to the clinical pathway should maintain much-appreciated privacy, anonymity and confidentiality. POCTs may improve YP's experiences of attending SHCs, which may not only remove barriers to testing, but also facilitate attendance.

Table 2. Recommendations for implementation of POCTs at SHCs 
Recommendations

- $\quad$ Provide information for patients upon triage about the POCT, different pathways depending on results and possible timelines.

- $\quad$ Ensure patients are aware that they might receive results that day

- Discrete provision of self-sampling kits and information on self-sampling methods

- Continue clinic commitment to high levels of patient care, ensure that all staff all staff are trained to give results in clinic

- POCTs should be used as a tool in a consultation, with patients still given opportunity to discuss reason for attending before receiving results

\author{
List of abbreviations \\ AMR antimicrobial resistance \\ CT Chlamydia trachomatis \\ MG Mycoplasma genitalium \\ NAAT nucleic acid amplification test \\ NHS National Health Service \\ NG Neisseria gonorrhoeae \\ POCT point-of-care test \\ SHC sexual health clinic \\ SHS sexual health service \\ STI sexually transmitted infection \\ YP young people
}

\title{
Declarations
}

\section{Ethical approval and consent to participate}

Ethical approval was given in June 2015 by the London Bridge Research Ethics Committee, reference 15/LO/0535: Developing patient-centred, rapid, Point-of-Care testing including antimicrobial resistance markers for specialist sexual health services in the NHS: the Precise study social science programme. Favourable ethical approval for this analysis, focusing specifically on YP as a sub-group within the first qualitative Precise study, was given by the London School of Hygiene and Tropical Medicine Ethics Committee on 15th May 2017, reference 13493. All participants received an information sheet and signed a consent form.

\section{Consent for publish}

All participants gave their full informed written consent prior to data collection, not only for participation but for their anonymised data to be used in reports and publications.

\section{Availability of data and materials}

These data are restricted due to containing information that contain sensitive participant details including private medical information. Data that support the findings of this report may be made available to researchers, on request: https://doi.org/10.24376/rd.sgul.7660790.v1, or contact St George's University of London Research Data Support directly (researchdata@sgul.ac.uk) with their contact details and reason for their request.

\section{Competing interests}


ADREU has received funding from binx health (formerly Atlas Genetics Ltd), Alere, Cepheid, SpeedDx, Mologic, Revolugen and Sekisui. SSF has been a member of the BD Diagnostics Advisory Panel on UK Provision of Sexual Health Services.

\section{Funding}

This report is independent research funded as part of the National Institute for Health Research Invention for Innovation grant: A Point of Care Antimicrobial Resistance test for Neisseria gonorrhoeae and Mycoplasma genitalium infection. Ensuring accurate therapy and antibiotic stewardship in sexual health medicine. Reference: II-LB-0214-20005. St George's University of London Applied Diagnostic Research and Evaluation Unit (ADREU) acknowledges the support of the National Institute of Health Research Clinical Research Network (NIHR CRN). The funders had no role in study design, data collection and analysis, decision to publish, or preparation of the manuscript. The views expressed are those of the authors and not necessarily those of the NIHR, binx health, the NHS or the Department of Health. No funding was sought for this subset analysis.

\section{Authors' contributions}

HM conceived of the YP study, led the analysis and drafting of the manuscript. AP contributed to the analysis. RG contributed to YP study design. STS conceived of and led the overall Precise study. SSF conceived of and led the Precise study social science programme, interviewed participants and contributed to YP study design and analysis. All authors provided important input to the manuscript.

\section{Acknowledgements}

We are grateful to the young patients who participated in this study, and to the clinicians and experts who contributed to the Precise social science study.

\section{Author's information}

1. London School of Hygiene and Tropical Medicine, Faculty of Public Health and Policy, Department of Health Services Research and Policy; London, United Kindgom

2. St George's University of London, Applied Diagnostic Research and Evaluation Unit, Institute for Infection and Immunity; London, United Kindgom

3. St George's University Hospitals NHS Foundation Trust; London, United Kindgom

\section{References}

1. Public Heath England. Sexually Transmitted Infections and Chlamydia Screening in England. Heal Prot Rep 2016. 2017;11(20).

2. Sonnenberg P, Clifton S, Beddows S, Field N, Soldan K, Tanton C, et al. Prevalence, risk factors, and uptake of interventions for sexually transmitted infections in Britain: findings from the National Surveys of Sexual Attitudes and Lifestyles (Natsal). Lancet (London, England) [Internet]. 2013 Nov 30 [cited 2017 May 7];382(9907):1795-806. Available from: http://www.ncbi.nlm.nih.gov/pubmed/24286785

3. Public Heath England. NCSP: Programme overview [Internet]. 2003. Available from: https://www.gov.uk/government/publications/ncsp-programme-overview/ncsp-programmeoverview

4. SHL - Sexual Health London [Internet]. [cited 2019 Jan 6]. Available from: https://www.shl.uk/

5. Saunders JM, Mercer CH, Sutcliffe LJ, Hart GJ, Cassell J, Estcourt CS. Where do young men 
want to access STI screening? A stratified random probability sample survey of young men in Great Britain. Sex Transm Infect [Internet]. 2012 Oct [cited 2019 Jan 6];88(6):427-32.

Available from: http://www.ncbi.nlm.nih.gov/pubmed/22510331

6. Qadeer U, Oakeshott P, Patel R, Ali A, Theodorsson M, Kundasamy P. Where have young men been screened for STIs? Sex Transm Infect [Internet]. 2013 Mar 1 [cited 2019 Jan 6];89(2):107. Available from: http://www.ncbi.nlm.nih.gov/pubmed/23241966

7. Dixon-Woods M, Stokes T, Young B, Phelps K, Windridge K, Shukla R. Choosing and using services for sexual health: a qualitative study of women's views. Sex Transm Infect [Internet]. 2001 Oct [cited 2017 May 7];77(5):335-9. Available from: http://www.ncbi.nlm.nih.gov/pubmed/11588278

8. Scoular A, Duncan B, Hart G. "That sort of place....where filthy men go...": a qualitative study of women's perceptions of genitourinary medicine services. Sex Transm Infect [Internet]. 2001 Oct [cited 2017 Feb 17];77(5):340-3. Available from:

http://www.pubmedcentral.nih.gov/articlerender.fcgi?artid=1744369\&tool=pmcentrez\&ren dertype=abstract

9. Nwokolo N, McOwan A, Hennebry G, Chislett L, Mandalia S. Young people's views on provision of sexual health services. Sex Transm Infect [Internet]. 2002 Oct [cited 2017 Mar 31];78(5):342-5. Available from: http://www.ncbi.nlm.nih.gov/pubmed/12407236

10. Reeves C, Whitaker R, Parsonage R, Robinson C, Swale K. Sexual health services and education: Young people's experiences and preferences. Health Educ J [Internet]. 2006 [cited 2017 Mar 31];65(4):369-79. Available from: http://journals.sagepub.com/doi/pdf/10.1177/0017896906069381

11. Richardson D, Maple K, Perry N, Ambler E, Jurd C, Fisher M. A pilot qualitative analysis of the psychosocial factors which drive young people to decline chlamydia testing in the UK: implications for health promotion and screening. Int J STD AIDS [Internet]. 2010 Mar [cited 2017 May 7];21(3):187-90. Available from: http://www.ncbi.nlm.nih.gov/pubmed/20215623

12. Balfe $M$, Brugha $R, O^{\prime}$ Connell E, Vaughan D, O' Donovan D. Men's attitudes towards chlamydia screening: a narrative review. Sex Health [Internet]. 2010 May [cited 2017 May 7];9(2):120-30. Available from: http://www.ncbi.nlm.nih.gov/pubmed/22498155

13. Mckeown E, Doerner R, Nelson S, Low N, Robinson A, Anderson J, et al. The experiences of ethnic minority MSM using NHS sexual health clinics in Britain. Sex Transm Infect [Internet]. 2012 Dec [cited 2017 Feb 17];88(8):595-600. Available from: http://www.ncbi.nlm.nih.gov/pubmed/22717471

14. Normansell R, Drennan VM, Oakeshott P. Exploring access and attitudes to regular sexually transmitted infection screening: the views of young, multi-ethnic, inner-city, female students. Health Expect [Internet]. 2016 Apr [cited 2017 May 7];19(2):322-30. Available from: http://www.ncbi.nlm.nih.gov/pubmed/25703741

15. Stone N, Ingham R. When and Why Do Young People in the United KingdomFirst Use Sexual Health Services? Perspect Reprod Sex Heal. 2003;35(3):114-20.

16. World Health Organization. WHO Guidelines for the Treatment of Neisseria gonorrhoeae [Internet]. Geneva; 2016 [cited 2018 Jun 3]. Available from: http://apps.who.int/iris/bitstream/handle/10665/246114/9789241549691eng.pdf;jsessionid=82FB506FDC67239D79F84836CBA6871D?sequence $=1$

17. Ndowa FJ, Ison CA, Lusti-Narasimhan M. Gonococcal antimicrobial resistance: the 
implications for public health control. Sex Transm Infect [Internet]. 2013 Dec 1 [cited 2018 Jun 3];89 Suppl 4(Suppl 4):iv1-2. Available from:

http://www.ncbi.nlm.nih.gov/pubmed/24243872

18. Sadiq ST, Mazzaferri F, Unemo M. Rapid accurate point-of-care tests combining diagnostics and antimicrobial resistance prediction for Neisseria gonorrhoeae and Mycoplasma genitalium. Sex Transm Infect [Internet]. 2017 Dec 1 [cited 2018 May 31];93(S4):S65-8. Available from: http://www.ncbi.nlm.nih.gov/pubmed/28684610

19. Bignell C, Fitzgerald $M$, et al. UK national guideline for the management of gonorrhoea in adults, 2011. Int J STD AIDS [Internet]. 2011 [cited 2018 May 31];22(10):541-7. Available from: https://www.bashhguidelines.org/media/1044/gc-2011.pdf

20. Public Health England. Infection report: HIV-STIs. Heal Prot Rep . 2016;10(22).

21. National Institute of Health Research. Research priorities: Anti-microbial resistance [Internet]. 2017. Available from: https://www.nihr.ac.uk/research-and-impact/researchpriorities/antimicrobial-resistance.htm

22. British Association for Sexual Health and HIV. United Kingdom National Guideline for Gonorrhoea Testing [Internet]. 2012. Available from: https://www.bashh.org/documents/4490.pdf

23. Pai M, Ghiasi M, Pai N. Point-of-care diagnostic testing in global health: what is the point? Microbe. 2015;10(3):103-7.

24. Natoli L, Maher L, Shephard M, Hengel B, Tangey A, Badman S, et al. Point-of-Care Testing for Chlamydia and Gonorrhoea: Implications for Clinical Practice. PLoS One. 2014;9(6).

25. Harding-Esch EM, Nori A V, Hegazi A, Pond MJ, Okolo O, Nardone A, et al. Impact of deploying multiple point-of-care tests with a "sample first" approach on a sexual health clinical care pathway. A service evaluation. Sex Transm Infect [Internet]. 2017 Sep 1 [cited 2018 Jun 6];93(6):424-9. Available from: http://www.ncbi.nlm.nih.gov/pubmed/28159916

26. Atkinson L, Vijeratnam D, Mani R, Patel R. The waiting game': are current chlamydia and gonorrhoea near-patient/point-of-care tests acceptable to service users and will they impact on treatment? Int J STD AIDS. 2015;27(8):650-5.

27. Jain A, Ison C. Chlamydia point-of-care testing: Where are we now? Sex Transm Infect. 2013;89(2):88.

28. Eaton S, Biggerstaff D, Pink J, Petrou S, Osipenko L, Gibbs J, et al. Factors affecting young people's preferences for emerging technologies for chlamydia testing and treatment: a discrete choice experiment in England. Lancet. 2016;288.

29. Lam S, Baros H, O'Grady M, Slack-Smith L. Patterns of Attendance of Children Under 12 Years at School Dental Service in Western Australia. Open Dent J. 2012;6.

30. Bjerregaard A-L, Maindal HT, Bruun NH, Sandbæk A. Patterns of attendance to health checks in a municipality setting: the Danish "Check Your Health Preventive Program". Prev Med reports [Internet]. 2017 Mar [cited 2018 Feb 12];5:175-82. Available from: http://www.ncbi.nlm.nih.gov/pubmed/28050340

31. Cook L, Fleming C. Analysis of clinic attendances by under-14s to sexual health clinics in Gwent, South Wales, UK. J Fam Plan Reprod Heal Care [Internet]. 2007 Jan 1 [cited 2018 Feb 12];33(1):23-6. Available from: http://www.ncbi.nlm.nih.gov/pubmed/17389091

32. Shepherd L, Harwood $\mathrm{H}$. The role of STI-related attitudes on screening attendance in young 
adults. Psychol Health Med [Internet]. 2017 Jul 3 [cited 2017 May 8];22(6):753-8. Available from: http://www.ncbi.nlm.nih.gov/pubmed/27636824

33. Wolfers ME, Kok G, Mackenbach JP, de Zwart O. Correlates of STI testing among vocational school students in the Netherlands. BMC Public Health [Internet]. 2010 Dec 24 [cited 2018 Mar 27];10(1):725. Available from:

http://bmcpublichealth.biomedcentral.com/articles/10.1186/1471-2458-10-725

34. Fuller SS, Pacho A, Broad CE, Nori A V., Harding-Esch EM, Sadiq ST. "It's not a time spent issue, it's a 'what have you spent your time doing?' issue..." A qualitative study of UK patient opinions and expectations for implementation of Point of Care Tests for sexually transmitted infections and antimicrobial resistance. Galea JT, editor. PLoS One [Internet]. 2019 Apr 16 [cited 2019 Apr 29];14(4):e0215380. Available from: http://dx.plos.org/10.1371/journal.pone.0215380

35. Chelsea and Westminister Hospital NHS Foundation Trust. Home | Dean Street Express [Internet]. [cited 2019 Jan 12]. Available from: http://express.dean.st/

36. Ritchie J, Spencer L, O’ Connor W. Chapter 9: Carrying out Qualitative Analysis. In: Ritchie J, Lewis J, editors. Qualitative Research Practice: A guide for Social Science Students and Researchers. London, UK: SAGE; 2003.

37. Rompalo A, Hsieh $\mathrm{Y}$, Hogan $\mathrm{T}$, Barnes $\mathrm{M}$, Jett-Goheen $\mathrm{M}$, Huppert J, et al. Point-of-care tests for sexually transmissible infections: what do 'end users' want? Sex Health. 2013;10(6):5415.

38. Cleary M, O'Sullivan J. P145 London sexual health transformation programme. Sex Transm Infect [Internet]. 2017 Jun 1 [cited 2019 Jan 24];93(Suppl 1):A64-5. Available from: https://sti.bmj.com/content/93/Suppl_1/A64.3.citation-tools

39. London Councils. Sexual Health London | London Councils [Internet]. [cited 2019 Jan 24]. Available from: https://www.londoncouncils.gov.uk/our-key-themes/health-and-adultservices/public-health/sexual-health-0/london-sexual-health

40. Wilson E, Free C, Morris TP, Syred J, Ahamed I, Menon-Johansson AS, et al. Internet-accessed sexually transmitted infection (e-STI) testing and results service: A randomised, single-blind, controlled trial. Broutet N, editor. PLOS Med [Internet]. 2017 Dec 27 [cited 2018 Oct 22];14(12):e1002479. Available from: http://www.ncbi.nlm.nih.gov/pubmed/29281628

41. Barnard S, Free caroline, Bakolis ioannis, turner KM, looker KJ, Baraitser P. Comparing the characteristics of users of an online service for STI self-sampling with clinic service users: a cross-sectional analysis. Sex Transm Infect [Internet]. 2018 [cited 2019 Jan 23];94:377-83. Available from: http://sti.bmj.com/

42. Friedman AL, Bloodgood B. Exploring the Feasibility of Alternative STD-Testing Venues and Results Delivery Channels for a National Screening Campaign. Health Promot Pract [Internet]. 2013 Jan [cited 2017 May 8];14(1):96-104. Available from: http://www.ncbi.nlm.nih.gov/pubmed/21965593

43. Llewellyn CD, Sakal C, Lagarde M, Pollard A, Miners AH. Testing for sexually transmitted infections among students: a discrete choice experiment of service preferences. BMJ Open [Internet]. 2013 Oct 28 [cited 2017 Apr 2];3(10):e003240. Available from: http://www.ncbi.nlm.nih.gov/pubmed/24165028

44. Aicken CRH, Fuller SS, Sutcliffe LJ, Estcourt CS, Gkatzidou V, Oakeshott P, et al. Young people's perceptions of smartphone-enabled self-testing and online care for sexually transmitted 
infections: qualitative interview study. BMC Public Health [Internet]. 2016 Sep 13 [cited 2017 May 7];16(1):974. Available from: http://www.ncbi.nlm.nih.gov/pubmed/27624633

45. Office for National Statistics. Ethnicity and National Identity in England and Wales 2011 [Internet]. 2012. Available from:

http://webarchive.nationalarchives.gov.uk/20160107112033/http://www.ons.gov.uk/ons/dc p171776_290558.pdf

46. Datta J, Reid D, Hughes G, Mercer CH, Wayal S, Weatherburn P. Places and people: the perceptions of men who have sex with men concerning STI testing: a qualitative study. Sex Transm Infect [Internet]. 2018 Feb [cited 2018 Feb 12];94(1):46-50. Available from: http://sti.bmj.com/lookup/doi/10.1136/sextrans-2016-052983

47. Beck A, Majumdar A, Estcourt C, Petrak J, Beck A. "'We don't really have cause to discuss these things, they don't affect us'": a collaborative model for developing culturally appropriate sexual health services with the Bangladeshi community of Tower Hamlets. [cited 2018 Jun 24]; Available from: http://sti.bmj.com/content/sextrans/81/2/158.full.pdf

48. Public Health England. Sexually transmitted infections and screening for chlamydia in England, 2017. Heal Prot Rep [Internet]. 2018 [cited 2018 Jun 24];12(20). Available from: https://assets.publishing.service.gov.uk/government/uploads/system/uploads/attachment_d ata/file/713944/hpr2018_AA-STIs_v5.pdf

49. Furegato $\mathrm{M}$, Chen $\mathrm{Y}$, Mohammed H, Mercer CH, Savage EJ, Hughes G. Examining the role of socioeconomic deprivation in ethnic differences in sexually transmitted infection diagnosis rates in England: evidence from surveillance data. 2016 [cited 2019 Jan 20]; Available from: https://doi.org/10.1017/\$0950268816001679

50. Low N, Sterne JA, Barlow D. Inequalities in rates of gonorrhoea and chlamydia between black ethnic groups in south east London: cross sectional study. Sex Transm Infect [Internet]. 2001 Feb [cited 2019 Jan 21];77(1):15-20. Available from: http://www.ncbi.nlm.nih.gov/pubmed/11158686

51. Fenton KA, Mercer CH, McManus S, Erens B, Wellings K, Macdowall W, et al. Ethnic variations in sexual behaviour in Great Britain and risk of sexually transmitted infections: a probability survey. Lancet [Internet]. 2005 Apr [cited 2019 Jan 21];365(9466):1246-55. Available from: http://www.ncbi.nlm.nih.gov/pubmed/15811458

52. Wayal S, Hughes G, Sonnenberg P, Mohammed H, Copas AJ, Gerressu M, et al. Ethnic variations in sexual behaviours and sexual health markers: findings from the third British National Survey of Sexual Attitudes and Lifestyles (Natsal-3). Lancet Public Heal [Internet]. 2017 Oct 1 [cited 2019 Jan 21];2(10):e458-72. Available from: http://www.ncbi.nlm.nih.gov/pubmed/29057382

53. All-party parliamentary group on reproductive and sexual health (APPGSRH). Breaking down the barriers: The need for accountability and integration in sexual health, reproductive health and HIV services in England [Internet]. 2017. Available from:

http://www.fpa.org.uk/sites/default/files/breaking-down-the-barriers-report-appg-srhuk.pdf 